\title{
Transferring Tacit Knowledge in Process Control
}

\author{
Anna-Lisa Osvalder and Anders Colmsjö
}

\begin{abstract}
Experienced operators, who have worked in process industry for many years possess extensive tacit knowledge regarding how to operate and control the plant. The purpose of this study was to propose methods for knowledge transfer regarding process control. Four conditions are important for successful knowledge transfer: resources from the management, access to a control room environment, access to saved process data from incidents and disturbances, and motivated experienced operators with verbal skills. Methods recommended for catching tacit knowledge regarding process control are observations in the control room, operators using the think-aloud methodology during work, and expert operators creating and analyzing scenarios of disturbances. Methods for transfer tacit knowledge are scenario analysis of disturbances in focus groups, or role-play between experienced and novice operator. Also informal and spontaneous methods for knowledge transfer can be successful.
\end{abstract}

Keywords Tacit knowledge - Process control • Operator control • Expert • Methods

\section{Introduction}

To perform well an organization is dependent on the employees' competence. In an organization exposed to competition, knowledge is further a critical asset [1]. Studies have shown that a lot of explicit and implicit knowledge in an organization is hidden and synthesized among employees [2,3]. Employees move over time in and out of the organization due to termination of the employment, new recruit-

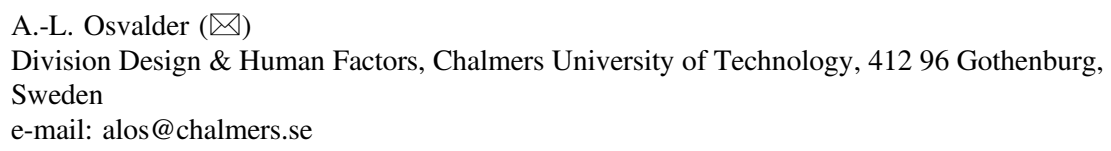

A. Colmsjö

Stockholm University, 10691 Stockholm, Sweden 
ments, organizational change or retirements. Then, there is a large risk that important knowledge disappears when experienced people leave the organization [4].

People who have worked in an organization for many years possess extensive tacit knowledge regarding how to perform their working tasks. Tacit knowledge develops through practice over a long period of time. It is implicit in nature and not easy accessible for verbalization in speech or writing. It is often very difficult to describe orally how a complex working task should be performed without explicitly showing how to do it.

An important distinction is found between knowledge that an individual has difficulties to verbalise (tacit) or not want to verbalize (hidden). The fact that a person do not want to verbalize some knowledge could be that otherwise others can take over his/her working tasks, or if the knowledge becames public it could result in negative consequences for the individual or the organization.

Regarding studies of tacit knowledge, these have mainly been implemented in large information organizations such as IT-companies, banks, service companies and consulting firms. Here it is considered that knowledge sharing between employees is important for business success. Within these organizations informal methods are often used in order to transfer tacit knowledge [5]. Mentoring and apprenticeship, coaching, job rotation and personal networking are examples of situations where tacit knowledge can be transferred. However there are few organizations using formalized methods for knowledge transfer. It is also very seldom that evaluations are made if knowledge transfer has been accomplished in an organization or which effects it might have given.

Few studies are found regarding tacit knowledge in safety critical organizations such as process industry and control room operation. In process industry experienced operators and shift teams stand for vital knowledge about operation and control of the plant, both as explicit and implicit knowledge. Larsson et al. (2007) [6] discuss, related to the nuclear sector, the importance of preserve competence within the organisation by taking care of older employees competence when retired and when generational shifts occur. Engstrom (2014) [7] also shows for the nuclear sector, how operators' skills and experience can act as a safety method for process control, especially when handling unexpected events. Methods for knowledge transfer that are used today in process industry are internship and teamwork in shift teams [6]. Here, tacit knowledge of one person is transferred to tacit knowledge of others through socialization [8], which takes several years and the result is seldom documented.

One prerequisite for safety and efficiency in the process industry today and in the future is to increase the awareness of the older expert operators' unique tacit knowledge regarding how to control and operate the plant. The purpose of this project was to propose suitable methods for finding expert operators' tacit knowledge regarding process control and transfer this knowledge into the organization to be used for education and training of operators and new employees. The tacit knowledge should be associated with understanding, judgment and problem solving of critical operational situations. This knowledge deals with which 
information, cues and patterns as well as which support systems that should be used to get a complete picture of the process status [9]. The project was conducted in collaboration with a process industry company responsible for operation and surveillance of the district heating system in a major city in Sweden.

\section{Methods}

As a basis for the proposals of methods for fining and transferring tacit knowledge regarding process control, literature studies were conducted. Furthermore interviews, observations, and questionnaires were performed within the process industry included in the project.

The literature studies dealt with definitions of tacit knowledge [10], and how this knowledge is stored in our memory [11]. Moreover knowledge conversion [8] has been studied as well as prerequisites and methods for knowledge transfer in various domains. Furthermore, the literature studies have considered characteristics for process control [12] and common working tasks performed in the control room environment, as well as the demands on operators, especially during unexpected events. Situational awareness, mental models and automation have also been studied related to process control.

In-depth interviews were performed occasionally during 1 year, with three skillful operational control engineers at the company. They had more than 15 years of experience of process control, control room work and how the various decision support systems function.

Observations were made in the control room on three occasions during $3 \mathrm{~h}$ each. Three different shift teams were then observed. Especially the type of information and which support systems that were used during work were studied, as well as how the team operators were communicating with each other.

Questionnaires were also distributed to all 42 operators in the six teams. The questionnaire dealt with what type of support they used for operation and control of the system, including everything from specific detailed information shown on screens to various type of help from colleagues. Also when and how often a specific support system was used were asked for.

\section{Results}

\subsection{Conditions for Knowledge Transfer}

From the literature studies together with all study visits at the process control company, four conditions were found to be desirable for successful transfer of tacit knowledge regarding process control within a process industry organization. 
The four conditions were: interest and resources from the management of the organization, possibility to perform knowledge transfer in the control room environment (or in a simulator), access to saved process data from disturbances and incidents, and motivated experienced operators with verbal skills and interest in knowledge sharing.

\subsection{Methods for Knowledge Transfer}

The following methods were proposed to be used in a process industry company for knowledge transfer regarding process control.

1. Methods for mapping the situation of the actual control room system

2. Methods for finding tacit knowledge

3. Methods for transferring tacit knowledge

\subsection{Methods for Mapping the Situation}

The situation includes the following parts: working tasks performed in the control room, the control room operators' experience, information and support systems available, and documentation of previous incidents and disturbances.

To map the situation access is needed to a number of experienced operators and key people in the company who have a great knowledge of the process, have been active in the control room for a long period of time (at least 10 years, preferably up to 20-25 years) and have been involved in problem solving of a number of disturbances and incidents of different severity. Interviews, questionnaires and observations should be used as data collection methods to map the situation.

\subsection{Methods for Finding Tacit Knowledge}

Methods to find the tacit knowledge of experienced process operators deal with trying to find and understand the heuristics and rules of thumb they use to solve complex upcoming situations. Three useful methods to catch tacit knowledge regarding process control are observations of individual operator as well as team performance in the control room, asking operators to use the think-aloud methodology during work, and requesting expert operators to carry out scenario analysis of process disturbances. 


\subsection{Methods for Transferring Tacit Knowledge}

Transferring tacit knowledge from experienced process operators to other operators deals with presenting information about the cues and patterns they use when they try to understand and solve problems during disturbances. Also of great interest is how they use different types of feedback from the system to judge how they should proceed the problem solving process. Furthermore, the expert operators' mental models of how the system is structured and functions are important to catch.

A useful method for transferring tacit knowledge regarding process control is scenario analysis of disturbances either in focus groups or as role-play between tutor and adept, i.e. the experienced operator teach an inexperienced operator.

Two useful methods for documentation of the tacit knowledge are checklists showing step by step how to perform a specific task, and compilation of heuristics and problem-solving strategies. Also development of a searchable incident report system including proposal for successful solutions is fruitful.

Informal methods for knowledge transfer can also be successful, such as net working, coffee break discussions and social activities. Tacit knowledge is then transferred to tacit knowledge through socialization, but the knowledge is not documented and available for all employees. These methods do not require much preparation or extra resources from the organization, but the frequency and content of the knowledge transfer is hard to catch and the effect on learning is not easy to measure.

\section{Discussion}

The result showed that the operators at the process industry included in the study had extensive tacit knowledge regarding how the process functions and how it should be operated and controlled during all types of operational cases. Their knowledge is not expressed or documented, which should be done before the older experienced operators disappear from the organization through retirements. There is no documentation available of how to use and interpret the information and support systems in the control room during disturbances. Their knowledge need to be transferred to other operators in the organisation, e.g. by creating a digital library of information and solution strategies for different types of disturbances and incidents. This can then be used to teach operators how to build knowledge in a faster way than by apprenticeship, of how to operate the system in a safe way. The methods proposed in this paper for finding and transferring tacit knowledge can be fruitful within the company.

The results showed that observations are possible to perform in the actual control room, scenarios of incidents can be created, and role-play between experienced operator and novice operator can be performed. However, the conditions for doing this are not always the most favorable within the company. The possibilities for 
individual expert operators to participate in such activities can be a problem when they are a part of a team with tight time schedules. Here the management needs to find resources to release time for them to participate in such activities and also being interested in developing a climate in the company where all employees see the benefits of knowledge transfer.

When performing observations in the control room during on-going operation, it is possible to identify what information and which support systems the operators use, and also to listen to how the team members discuss problem solving strategies during various events. However, it is rare that more serious disturbances arise during an observation period, therefore the observations mainly can focus on finding the tacit knowledge that is used in the daily routine work.

Transferring tacit knowledge to new employees in the control room environment means that you are staying in the right environment both during learning and training. As a novice you can then ask questions and forcing the experienced operator to explain the control actions performed. It is important that the operators who are mentors also have a developed verbal skills in addition to being an expert of the system. Informal social transfer, such as during coffee and lunch breaks, is also a source of learning as well as social events outside the company.

\section{Conclusion}

There are few organizations that have adopted knowledge transfer as part of their working process or using formal methods for transferring tacit knowledge.

In process industry tacit knowledge is often transferred to tacit knowledge through socialization by mentorship, team work and informal social activities. The knowledge is then not easy to document and transfer to all employees.

Four conditions are needed for transfer of tacit knowledge in an optimal way in a process industry company; interest and resources from the organization, possibilities to perform the work in a typical control room environment, access to saved process data from disturbances, and motivated experienced operators with verbal skills and interest in knowledge sharing.

For knowledge transfer regarding process control it is important to use methods that can capture the operators' mental model of the system and find the cues and patterns that they use to interpret the status of the process at various operating states and to predict the future.

The methods recommended for the process industry in terms of finding tacit knowledge are observations in the control room, using the think-aloud methodology during work in the control room, and expert operators creating and analysing scenarios of disturbances and incidents.

The recommended methods for transferring tacit knowledge within the process industry are mainly scenario analysis of disturbances in focus groups, or role-play 
between experienced operator and novice operator. Also informal and spontaneous methods for knowledge transfer can be successful, such as net working, coffee break discussions and social activities. These methods do not require much preparation or resources from the organization.

\section{References}

1. Teece, D.J.: Capturing value from knowledge assets. Calif. Manag. Rev. 40(3), 55-78 (1998)

2. Wah, L.: Making knowledge stick. Manag. Rev. pp. 24-29 (1999)

3. Lee, J.: Knowledge management: the intellectual revolution. IIE Solutions, 34-37 (2000)

4. Smith, E.A.: The role of tacit and explicit knowledge in the workplace. J. Knowl. Manag. 5(4), 311-321 (2001)

5. Lave, J., Wenger, E.: Situated Learning. Legitimate Peripheral Participation. Cambridge University Press, Cambridge (1991)

6. Larsson, A., Ohlsson, K., Roos, A.: Kompetensöverföring på svenska kärnkraftverk i samband med pensionsavgångar (In Swedish). SKI Rapport 2007:27 (2006)

7. Engström, M.: Yrkeskunnande som säkerhetsmetod vid svåra driftsituationer (In Swedish): Doctoral dissertation. KTH Royal Institute of Technology, Stockholm (2014)

8. Nonaka, I., Takeuchi, H.: The Knowledge Creating Company: How Japanese Companies Create the Dynamics of Innovation. Oxford Press, London (1995)

9. Klein G.: Applied Cognitive Task Analysis Job Aid. Klein Associates Inc, Fairborn

10. Baumard, P.: Tacit Knowledge in Organizations. Sage, London \& Thousand Oaks (1999)

11. Badeley, A.D.: Working Memory. U.K. Clarendon, Oxford (1996)

12. Tschirner S.: The GMOC Model: Supporting Development of Systems for Human Control. Digital Comprehensive Summaries of Uppsala Dissertations from the Faculty of Science and Technology, ISSN 1651-6214; 1237 (2015) 